\title{
Bionomics and Ecological Services of Megaloptera Larvae (Dobsonflies, Fishflies, Alderflies)
}

\author{
Sara Lariza Rivera-Gasperín ${ }^{1}$ (D), Adrian Ardila-Camacho ${ }^{2}\left(\mathbb{D}\right.$ and Atilano Contreras-Ramos ${ }^{1, *}$ (D) \\ 1 Instituto de Biología, UNAM, Depto. de Zoología, 04510 Ciudad de México, Mexico; zaralariza@gmail.com \\ 2 Posgrado en Ciencias Biológicas, UNAM, Sede Instituto de Biología, 04510 Ciudad de México, Mexico; \\ aardilac88@gmail.com \\ * Correspondence: acontreras@ib.unam.mx
}

Received: 11 February 2019; Accepted: 21 March 2019; Published: 27 March 2019

\begin{abstract}
Megaloptera belong to a large monophyletic group, the Neuropteroidea, together with Coleoptera, Strepsiptera, Raphidioptera, and Neuroptera. With the latter two, this order constitutes the Neuropterida, a smaller monophyletic subset among which it is the only entirely aquatic group, with larvae of all species requiring submersion in freshwater. Megaloptera is arguably the oldest extant clade of Holometabola with aquatic representatives, having originated during the Permian before the fragmentation of Pangea, since about 230 Ma. It includes 54 genera (35 extant and 19 extinct genera), with 397 extant described species and subspecies. Recent Megaloptera are divided into two families: Corydalidae (with subfamilies Corydalinae—dobsonflies and Chauliodinae-fishflies) and Sialidae (alderflies), both widely yet disjunctively distributed among zoogeographical realms. All species of Megaloptera have aquatic larvae, whereas eggs, pupae, and adults are terrestrial. The anatomy, physiology, and behavior of megalopteran larvae are specialized for an aquatic predatory habit, yet their ecological significance might still be underappreciated, as their role in food webs of benthic communities of many temperate and tropical streams and rivers is still understudied and largely unquantified. In many freshwater ecosystems, Megaloptera larvae are a conspicuous benthic component, important in energy flow, recycling of materials, and food web dynamics.
\end{abstract}

Keywords: immature insects; hellgrammites; insect diversity; fossil record; phylogeny; ecosystem services; adaptation; predation

\section{An Ancient Holometabolous Order}

The order Megaloptera Latreille, 1802, has been traditionally regarded as an ancient holometabolous group [1,2], and arguably includes the oldest known representatives of aquatic insects with complete metamorphosis. They are conceded slight attention by general or applied entomologists, yet aquatic entomologists are aware that they can attain high abundances in particular ecosystems and regions. Megaloptera include some of the most impressive insects, because of their large size (e.g., adult male Corydalus magnus Contreras-Ramos, 1998 with ca. $180 \mathrm{~mm}$ wingspan [3], mature larvae of Acanthacorydalis orientalis (McLachlan, 1899) with up to $90 \mathrm{~mm}$ body length [4]), and the odd appearance of males with elongate mandibles in some New World Corydalus and Oriental Acanthacorydalis [5] or a head with postocular expansions in Central American Platyneuromus [6,7]. With a comparatively low diversity of less than 400 extant described species and subspecies, their ecological role might be underappreciated, as megalopteran larvae or hellgrammites (Figure 1) can be relevant members of food webs in benthic communities of many temperate and tropical lakes, streams, and rivers. The extant species of Megaloptera are divided into two families: Corydalidae Leach, 1815, and Sialidae Leach, 1815 (alderflies), both widely distributed in all zoogeographical realms. The family Corydalidae is further divided into two subfamilies: Corydalinae Davis, 1903 (dobsonflies), 
and Chauliodinae van der Weele, 1909 (fishflies). All species of Megaloptera have aquatic larvae, whereas eggs, pupae, and adults of all species are terrestrial (Figure 2). Megaloptera are considered one of the ancient groups within holometabolous insects [8,9].

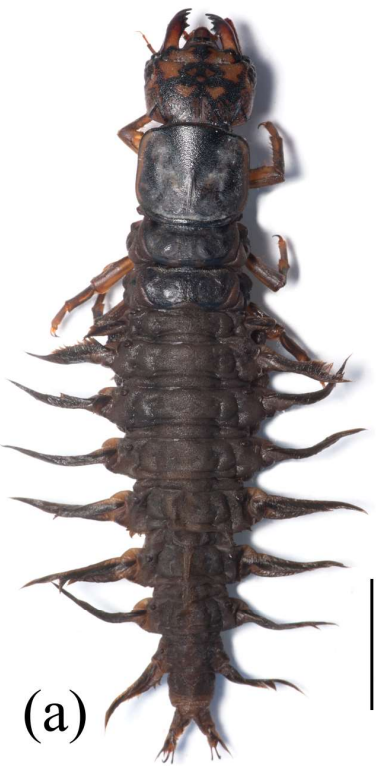

(b)
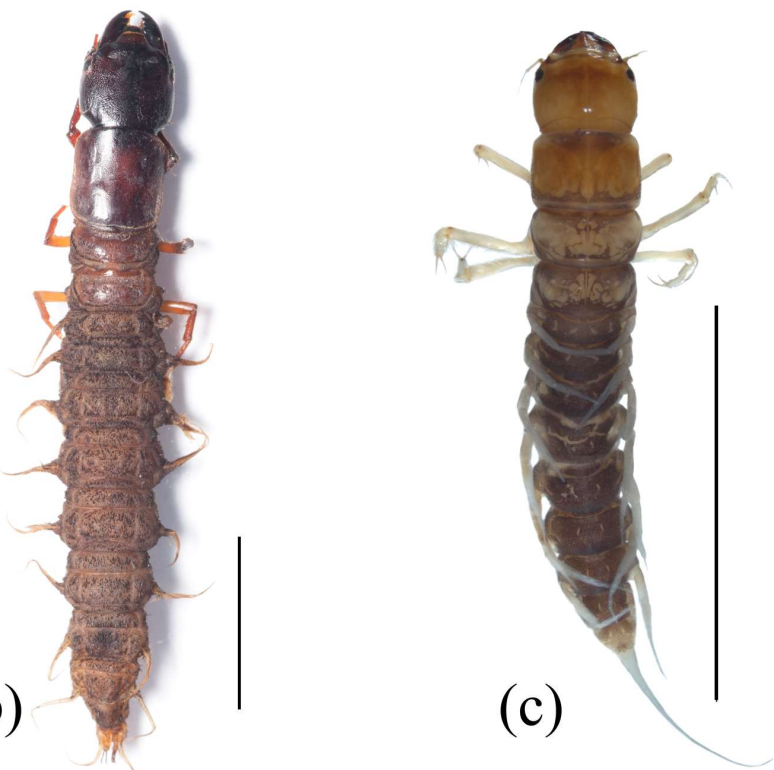

Figure 1. Habitus of Megaloptera larvae. (a) Corydalus liui Ardila-Camacho \& Contreras-Ramos, 2018, (b) Chloronia sp., (c) Ilyobius sp. Scale $=10 \mathrm{~mm}$. Images by Adrian Ardila-Camacho.
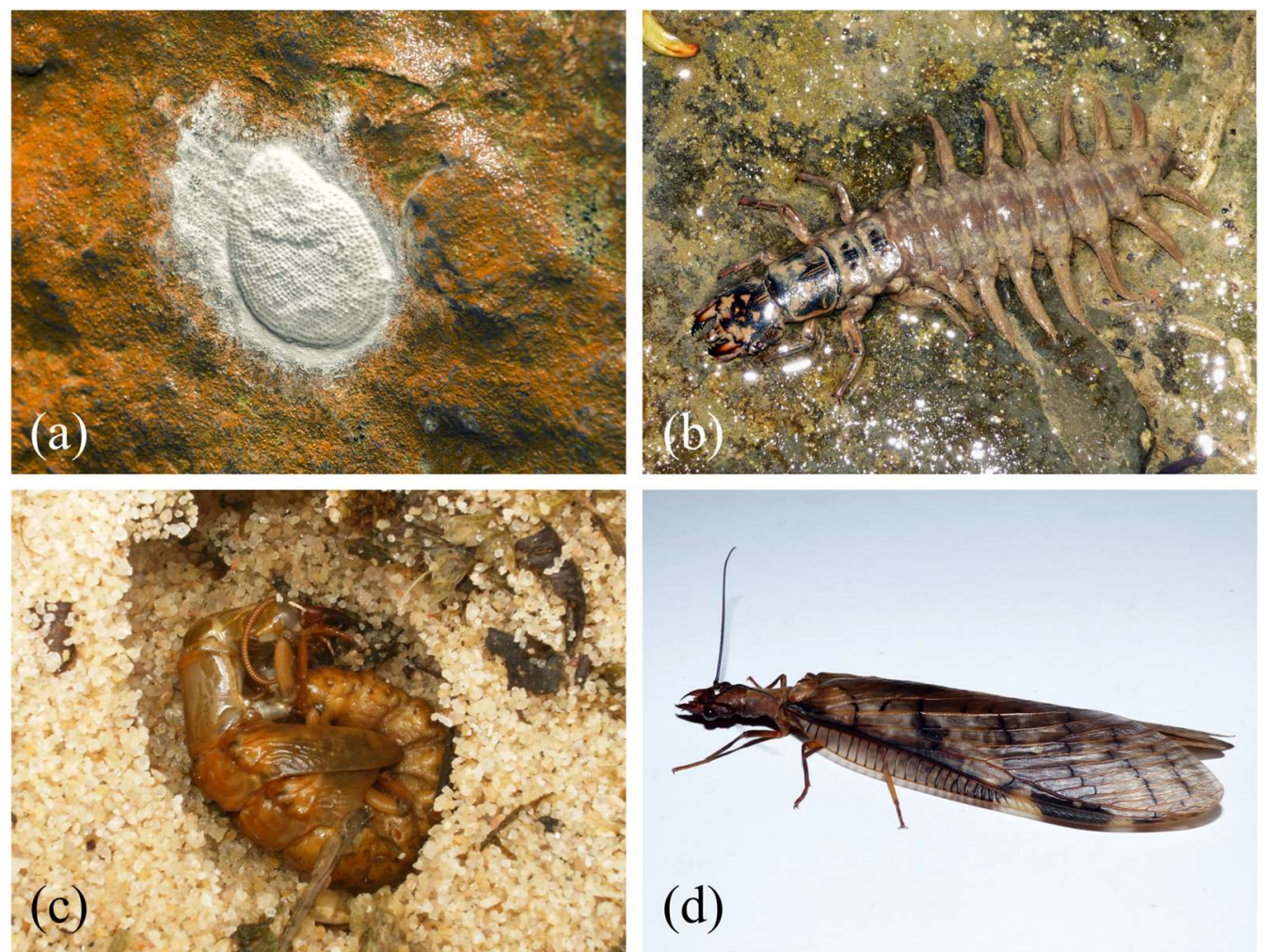

Figure 2. Developmental stages of Corydalus. (a) egg mass of Corydalus sp., (b) mature larva of Corydalus liui, (c) pupa of Corydalus peruvianus Davis, 1903, (d) female of Corydalus liui. Images by Adrian Ardila-Camacho. 


\section{Distribution and Diversity}

The order Megaloptera contains 52 genera represented by 397 extant described species and subspecies, distributed in 35 genera, and 34 extinct described species distributed in 24 extant and extinct genera (Tables 1 and 2) [8,10-13]. This order has a wide and fragmented geographical distribution, with Corydalinae (174 spp.) in the Americas, Asia, and South Africa; Chauliodinae (140 spp.) in North America, Argentina, Brazil, Chile, Australia, New Zealand, Madagascar, South Africa, Japan, and Southeast Asia; and Sialidae (83 spp.) in the Americas, Europe, Asia, South Africa, Madagascar, and Australia (Table 1) $[5,14,15]$. The main species richness centers of Corydalinae and Chauliodinae are China and Southeast Asia. A second region of high diversity in Corydalinae are Amazonia and the Andes Mountains. Chauliodinae is speciose in Australia and along the Pacific Coast of the United States, but is absent through most of the Neotropics, being restricted to Chile and southeastern Brazil [9]. Corydalidae are absent from Europe, the Middle East, Central Asia, tropical Africa, and boreal regions, with Corydalinae also absent from Australia [14]. Sialidae is most speciose in temperate regions and is absent from tropical Africa and portions of the Oriental region [14]. Several species are widespread (e.g., the South and Central American Corydalus peruvianus Davis, 1903, and the Amazonian C. affinis Burmeister, 1839), whereas others tend to be endemic and have restricted distributions (e.g., the western Mexican Chloronia pallida (Davis, 1903) or the Central American Platyneuromus reflexus Glorioso \& Flint, 1984). Endemism in Megaloptera is fairly common, even at the genus level (e.g., Chloroniella in South Africa, Dysmicohermes and Orohermes in western North America, Madachauliodes in Madagascar, and Apochauliodes and Austrosialis in Australia). Regarding the taxonomic knowledge of the larval stages, mature larvae are described for six genera of Corydalinae (Acanthacorydalis, Chloronia, Corydalus, Neoneuromus, Platyneuromus, and Protohermes), 13 genera of Chauliodinae (Apochauliodes, Archichauliodes, Chauliodes, Dysmicohermes, Madachauliodes, Neochauliodes, Neohermes, Nigronia, Orohermes, Parachauliodes, Platychauliodes, Protochauliodes, and Taeniochauliodes), and seven genera (Austrosialis, Haplosialis, Ilyobius, Indosialis, Leptosialis, Sialis, and Stenosialis) of Sialidae $[4,16-18]$.

Table 1. Genera of Megaloptera with extant valid species $\left({ }^{*}=\right.$ includes subspecies, ${ }^{* *}=$ possible erroneous combination of an Oriental species).

\begin{tabular}{|c|c|c|}
\hline Genus & Number of Species & Biogeographic Region \\
\hline \multicolumn{3}{|c|}{ CORYDALIDAE: Corydalinae } \\
\hline Acanthacorydalis van der Weele, 1907 & 8 & Oriental \\
\hline Chloronia Banks, 1908 & 18 & Nearctic, Neotropical \\
\hline Chloroniella Esben-Petersen, 1924 & 1 & Afrotropical \\
\hline Corydalus Latreille, 1802 & 39 & Nearctic, Neotropical, Oriental ${ }^{* *}$ \\
\hline Neoneuromus van der Weele, 1909 & 14 & Oriental, Palaearctic \\
\hline Neurhermes Navás, 1915 & 7 & Oriental \\
\hline Nevromus Rambur, 1842 & 6 & Oriental \\
\hline Platyneuromus van der Weele, 1909 & 3 & Nearctic, Neotropical \\
\hline Protohermes van der Weele, 1907 & 78 & Oriental, Palaearctic \\
\hline \multicolumn{3}{|c|}{ CORYDALIDAE: Chauliodinae } \\
\hline Anachauliodes Kimmins, 1954 & 1 & Oriental \\
\hline Apochauliodes Theischinger, 1983 & 1 & Australian \\
\hline Archichauliodes van der Weele, 1909 & 21 & Australian, Neotropical \\
\hline Chauliodes Latreille, 1802 & 2 & Nearctic \\
\hline Ctenochauliodes van der Weele, 1909 & 13 & Oriental \\
\hline Dysmicohermes Munroe, 1953 & 2 & Nearctic \\
\hline Madachauliodes Paulian, 1951 & 3 & Afrotropical \\
\hline Neochauliodes van der Weele, 1909 & 47 & Oriental, Palaearctic \\
\hline Neohermes Banks, 1908 & 6 & Nearctic \\
\hline Nigronia Banks, 1908 & 2 & Nearctic \\
\hline Nothochauliodes Flint, 1983 & 1 & Neotropical \\
\hline Orohermes Evans, 1984 & 1 & Nearctic \\
\hline Parachauliodes van der Weele, 1909 & 7 & Oriental, Palaearctic \\
\hline
\end{tabular}


Table 1. Cont.

\begin{tabular}{lcc}
\hline \multicolumn{1}{c}{ Genus } & Number of Species & Biogeographic Region \\
\hline & CORYDALIDAE: Chauliodinae & \\
Platychauliodes Esben-Petersen, 1924 & 3 & Afrotropical \\
Protochauliodes van der Weele, 1909 & $17^{*}$ & Australian, Nearctic, Neotropical \\
Puri Cardoso-Costa et al., 2013 & 1 & Neotropical \\
Sinochauliodes Liu \& Yang, 2006 & 4 & Oriental \\
Taeniochauliodes Esben-Petersen, 1924 & 8 & Afrotropical \\
\hline & SIALIDAE: Sialidinae & \\
Austrosialis Tillyard, 1919 & 2 & Australian \\
Haplosialis Navás, 1927 & 2 & Afrotropical \\
Ilyobius Enderlein, 1910 & 9 & Neotropical, Palaearctic \\
Indosialis Lestage, 1927 & 3 & Oriental, Palaearctic \\
Leptosialis Esben-Petersen, 1920 & 2 & Afrotropical \\
Protosialis van der Weele, 1909 & 3 & Nearctic, Neotropical \\
Sialis Latreille, 1802 & 60 & Nearctic, Oriental, Palaearctic \\
Stenosialis Tillyard, 1919 & 2 & Australian \\
\hline Total: 35 genera & $397 \mathrm{spp}$. \\
\hline
\end{tabular}

Table 2. Genera of Megaloptera with extinct valid species $(B R A=$ Brazil, $\mathrm{CAN}=$ Canada, $\mathrm{CHN}=\mathrm{China}$, DEU $=$ Germany, DOM = Dominican Republic, FRA $=$ France, MNG = Mongolia, RUS = Russia, TUR $=$ Turkey, USA = United States; ${ }^{*}=$ some species from amber deposits; + : extinct taxon).

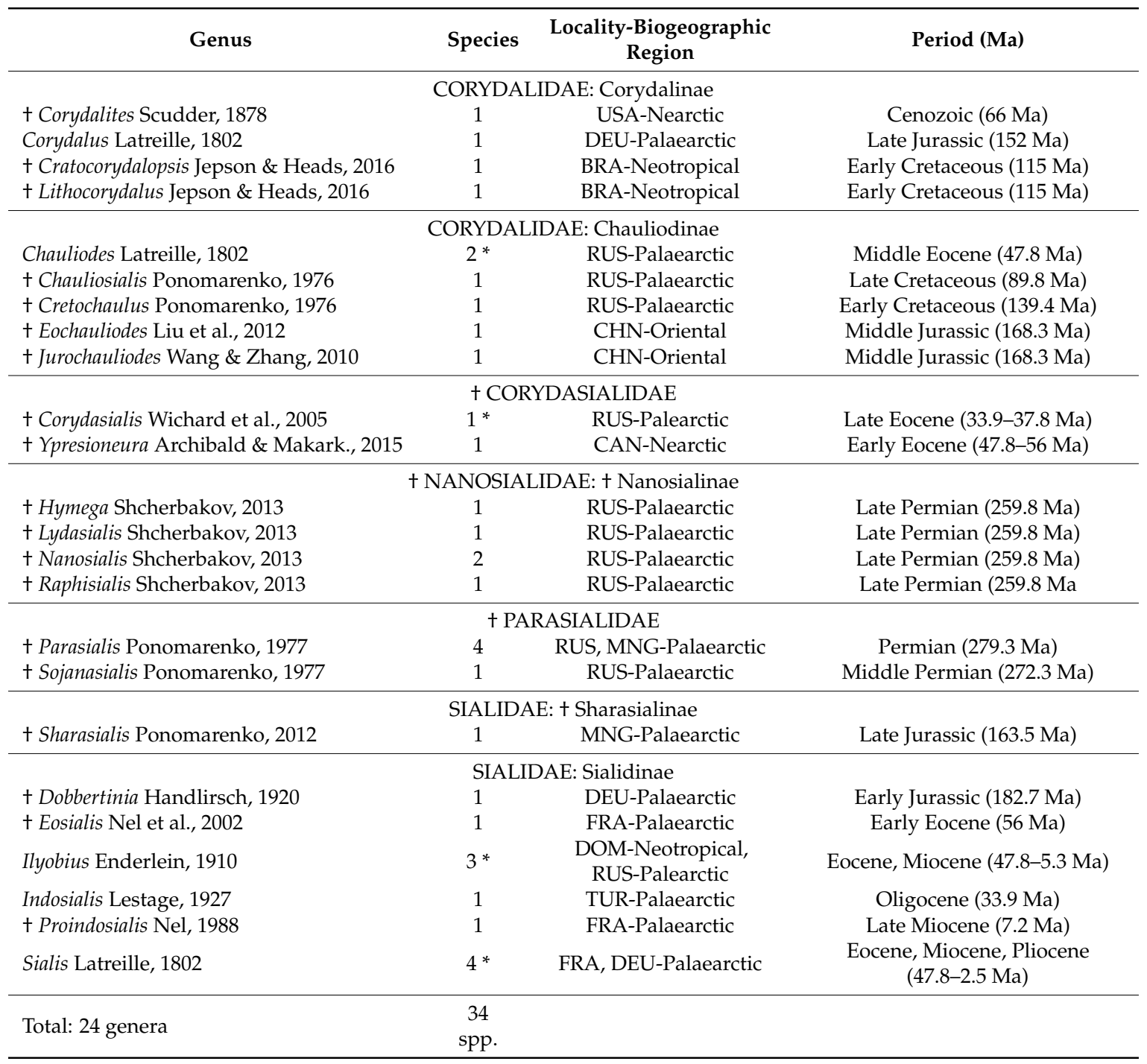




\section{Origin and Fossil Record}

Insects underwent an explosive radiation during the Carboniferous and early Permian, especially with the origin of holometabolous insects (= Holometabola), which later became the dominant multicellular organisms in most terrestrial and freshwater ecosystems [2,19]. Recent studies suggest that Megaloptera species have existed since the Permian, before the fragmentation of Pangea, with subsequent radiation of Gondwanan and Laurasian elements, represented at present by numerous fossil taxa known from various Mesozoic deposits, many placed in now-extinct families (Table 2) $[15,20]$.

The oldest fossils that have been described of Megaloptera correspond to representatives of the Russian-Mongolian family +Parasialidae, genera +Parasialis (279.3-272.3 Ma, Permian) and +Sojanasialis (272.3-268.8 Ma, Permian). The fossil record is older than the estimates of megalopteran origin of about 230 Ma proposed by Misof et al. [19], and more closely agrees with a recent estimation of a middle Permian origin [20]. The extinct Russian family +Nanosialidae was also described from the Permian (259.8-254.2 Ma), however, this family has been proposed as ancestral members of the snakefly lineage [21,22]. Larvae of Megaloptera are known in the middle Triassic of Grès des Vosges, France (André Nel, pers. comm.), whereas fossil genera of Sialidae, +Dobbertinia and +Sharasialis, are known from Old World Early and Late Jurassic deposits, respectively. The oldest representatives of Corydalidae belong to + Jurochauliodes and + Eochauliodes from the Mongolian-Chinese Middle Jurassic. However, splitting of the two main lineages, Corydalidae and Sialidae, might have been earlier, about 183 Ma during Middle Jurassic [10], or 210-215 Ma during late Triassic [19]. Other extinct corydalid genera are from Cretaceous deposits, both from the Old and New World (Table 2) [15,23]. More-recent species from extant and extinct genera have been described from the Cenozoic, mostly from the Eocene, Miocene, and Pliocene of Australia, Canada, Russia, Turkey, France, Germany, Dominican Republic, and the USA (Table 2) [23]. The neuropteroid family Corydasialidae was proposed from a specimen preserved in Baltic amber (late Eocene) [24]. A second species was assigned from a compressed forewing from the Ypresian (early Eocene) Okanagan Highlands, British Columbia, Canada [25]. This family is problematic because it possesses a generalized wing venation, and the characteristics used to place it within Megaloptera are not strongly diagnostic, yet a position in Megaloptera seems to be favored [25].

\section{Phylogenetic Relationships}

The order Megaloptera belongs to a large monophyletic group, the Neuropteroidea, together with the Coleoptera (beetles), Strepsiptera (twisted-wing parasites), Raphidioptera (snakeflies), and Neuroptera (lacewings). With the latter two, this order constitutes the Neuropterida, a smaller monophyletic subset, among which it is the only entirely aquatic group, with larvae of all species requiring submersion in freshwater $[8,20,26]$. For years, the sister group relationships within Neuropterida were contentious [2,27]; however, strong support has been provided recently that Megaloptera and Neuroptera are sister taxa $[19,20,26]$.

It has long been assumed that the Megaloptera are a natural group (e.g., [27]), in part because of similarity in larval morphology and common ecology (e.g., a small pair of lateral filaments on the eighth abdominal segment, predatory habits, and aquatic habitat). However, its monophyletic origin was challenged by recent morphological and molecular studies (e.g., [10,28,29]). Nonetheless, recent genomic analyses have confirmed the monophyly of Megaloptera $[11,13,19,20]$. Despite an old hypothesis supporting a sister relationship with Chauliodinae + Sialidae [30,31], recent molecular analyses support the sister relationship of Corydalinae + Chauliodinae (i.e., a monophyletic Corydalidae sister to Sialidae) (e.g., [11]).

A phylogeny of Corydalinae based on morphological characters [32] (Figure 3a) recognized four main dobsonflies lineages: (1) the monotypic Chloroniella from South Africa (as sister to all other lineages), much in agreement with a former analysis [33], except the latter placed Acanthacorydalis as sister to the New World lineage and Chloroniella was not included; (2) the Protohermes lineage that 
includes the primarily Oriental genera Protohermes and Neurhermes; (3) the Corydalus lineage, which includes the New World genera Corydalus, Platyneuromus, and Chloronia; and (4) the Nevromus lineage composed of the Oriental genera Nevromus, Neoneuromus, and Acanthacorydalis.

A phylogenetic analysis of Chauliodinae that included all fossil and extant genera [9] (Figure 3b) recognized three major clades within fishflies: (1) the Dysmicohermes lineage, which includes the western North American genera Dysmicohermes and Orohermes; (2) the Protochauliodes lineage, which includes Madachauliodes from Madagascar, Taeniochauliodes from South Africa, Neohermes from North America, Nothochauliodes from Chile, and the disjunctly distributed genus Protochauliodes from western North America, Chile, and Australia, as well as extinct fossil taxa found in Asia; and (3) the diverse Archichauliodes lineage, which includes Platychauliodes from South Africa, Chauliodes and Nigronia from North America, Apochauliodes from western Australia, Ctenochauliodes, Neochauliodes, Parachauliodes, and Sinochauliodes from the Oriental region, and the disjunct genus Archichauliodes from South America and Australia. In addition, Cardoso-Costa et al. [34] described the new monotypic genus Puri from Brazil, which appears to be a member of the Archichauliodes lineage [35].

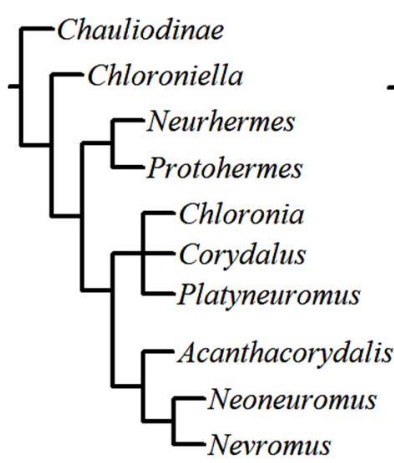

(a)
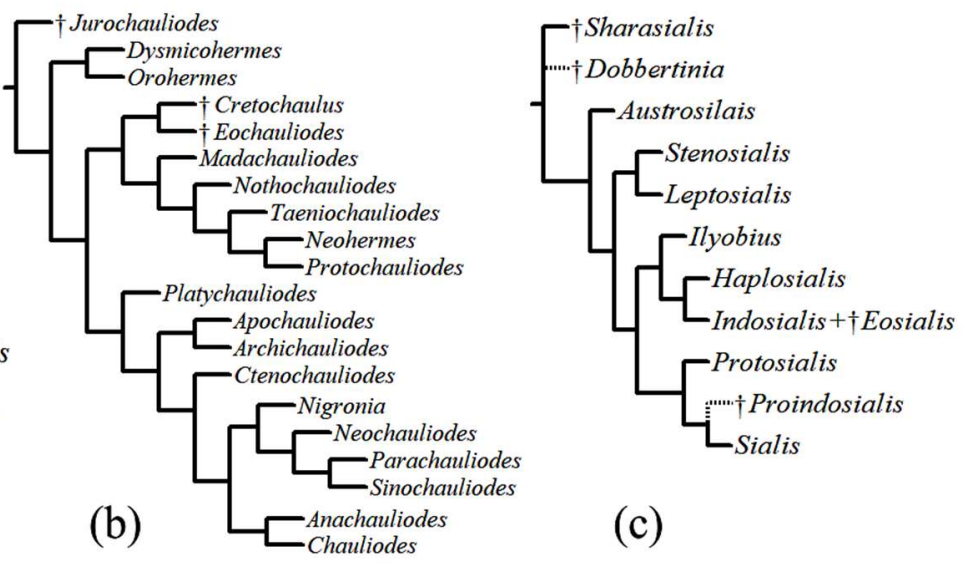

(c)

Figure 3. Phylogenetic trees. (a) phylogeny of Corydalinae proposed by Contreras-Ramos [32], (b) phylogeny of Chauliodinae proposed by Liu et al. [9], (c) phylogeny of Sialidae by Liu et al. [36] (putative positions indicated by dotted lines).

The first global phylogeny of Sialidae was based on morphological data [36] (Figure 3c). Its authors recognized two subfamilies: +Sharasialinae and Sialidinae. Within Sialidinae, the genus Austrosialis is sister to all other extant genera, an assemblage which includes three monophyletic lineages: (1) the Stenosialis lineage composed of Stenosialis from Australia and Leptosialis from South Africa; (2) the Ilyobius lineage composed of Ilyobius from the Neotropics, Haplosialis from Madagascar and Indosialis from Turkey, India, and Singapore; and (3) the Sialis lineage, which includes the species-rich genus Sialis from the Nearctic, Palearctic, and Oriental regions and the American Protosialis.

\section{Evolution of Ecological Roles}

As a member of the Neuropterida, Megaloptera maintain a generalized life history, with noteworthy differences in habitat and food preference only between families. In general, larval Megaloptera are voracious predators with some known to be scavengers; cannibalism might occur in all species [3,5]. Several alderfly species inhabit lentic habitats, or depositional zones of lotic systems, where they feed on small prey they can capture within the soft sediments (e.g., oligochaetes, chironomids, ostracods, or other small invertebrates). Dobsonfly larvae inhabit lotic waters, as most fishfly species do, except a few are associated with lentic environments (e.g., the North American Chauliodes). Yet, their polyphagous habits are a generalized trait for all Megaloptera, except perhaps for alderfly larvae associated with soft sediments (e.g., bottoms of lakes) and smaller prey, and one alderfly species has been reported as a collector-gatherer [37]. Larval Sialis consume small prey without 
chewing [5,38], but larger prey items are captured with mandibles and forelegs, a behavior that has also been observed in Corydalus [39]. It has been observed in captivity that once the prey is grasped, the larva manipulates it with the forelegs and the mouthparts to cut and swallow small portions [39]. Larval Corydalidae are ambush predators and are typically found under stones, submerged plant materials, roots, and logs. Their prey spectrum includes a wide variety of aquatic organisms, including other immature aquatic insects, crustaceans, worms, and tadpoles [5]. In laboratory conditions, mature larvae of Corydalus accepted different types of live and dead terrestrial arthropods, earthworms, small fishes, and even fresh fish meat as food. These predatory larvae remain motionless for long periods of time and often move to other suitable places during the night [40], probably searching for prey, as substrate type is correlated with the success of predation [41]. Size of the prey captured is positively correlated with the size of the mandibles, and consequently, with the size of the larva [42].

The ancestral environment for Megaloptera probably was lotic, with several alderfly species colonizing lentic habitats, particularly in temperate areas (e.g., Neotropical alderflies are mostly lotic); dobsonflies tend to inhabit tropical lotic habitats, whereas fishflies tend to be temperate [43], with at least the North American genus Chauliodes sometimes inhabiting lentic waters, including tree holes [44]. Several corydalid species inhabit intermittent streams, such as western North American fishflies Neohermes californicus (Walker, 1853), N. filicornis (Banks, 1903), Protochauliodes aridus Maddux, 1954, and P. spenceri Munroe, 1953 [43,45], or the dobsonflies Corydalus luteus Hagen, 1861, from Middle America and C. affinis Burmeister, 1839, from the Argentinean Chaco [3,46]. More specific relationships of habitat preference and geography appear to exist, with a gradient of species from those that are eurytopic and widespread to others that are stenotopic and endemic. Examples of the latter in Suriname include Corydalus nubilus Erichson, 1848, which appears to be confined to large open rivers, and C. batesii McLachlan, 1868, which seems to be restricted to creeks shaded by small bushes [47]. No analysis has been made yet globally to compare habitat restriction to pollution tolerance.

\section{Essential Services for Ecosystem Function}

Megaloptera larvae are found in clean lakes, ponds, and watercourses; however, some species tolerate some water pollution or anthropogenic eutrophication. In several freshwater ecosystems, these insects are a conspicuous component, important in energy flow, recycling of materials, and food chains [3,48]. The significance of the ecological role of larval Megaloptera rests upon their euryphagic, predatory habits, although many are probably also scavengers. These traits, particularly at higher population densities, make the group a significant element in trophic networks, and thus a contributor for the equilibrium of aquatic communities. Larvae of Corydalidae may be the largest and most abundant predator in fishless streams, and thus play an important role in food web dynamics [49]. Typically, the group regulates populations of other invertebrates, while also being an important prey for other invertebrates, fishes, and some terrestrial vertebrates [50]. Species of restricted distribution, often present in low population numbers, such as some Neotropical Sialidae, might play an important role for the conservation of their habitats [51].

\section{Food for Other Organisms and Uses for Humans}

Larval Megaloptera represent an important component of aquatic food webs [52] and constitute part of the diet of an important variety of organisms, including vertebrates and other invertebrates. Odonata naiads and predatory Trichoptera have been reported among the aquatic invertebrate enemies of Megaloptera, yet many other groups such as aquatic Coleoptera and Hemiptera may also prey on megalopteran larvae. Predatory fishes are probably the principal natural enemies of this group [53]. In South America, some species of the rodent Ichtyomys prey on mature larvae of Corydalus and Chloronia, and in Mexico pigs forage on Corydalus larvae [5,54]. In Mexico and other regions of Latin America, hellgrammites, particularly of the genus Corydalus, are used as food by human communities, and in North America are appreciated as fishing bait [50]; Acanthacorydalis larvae are used in traditional food and medicine in southwestern China [4], and dehydrated Protohermes larvae are used as infant 
tranquilizer in Japan [33]. Energy flow from the aquatic towards the terrestrial environment, based on considerable figures of secondary production by megalopteran larvae [55,56], is another understudied service of this biological group in neighboring freshwater and terrestrial ecosystems. At least one artist (Adam Pasamanick) has built a realistic bronze sculpture of a male Corydalus cornutus, now exhibited at the Fairbanks Museum and Planetarium in Vermont (Figure 4).

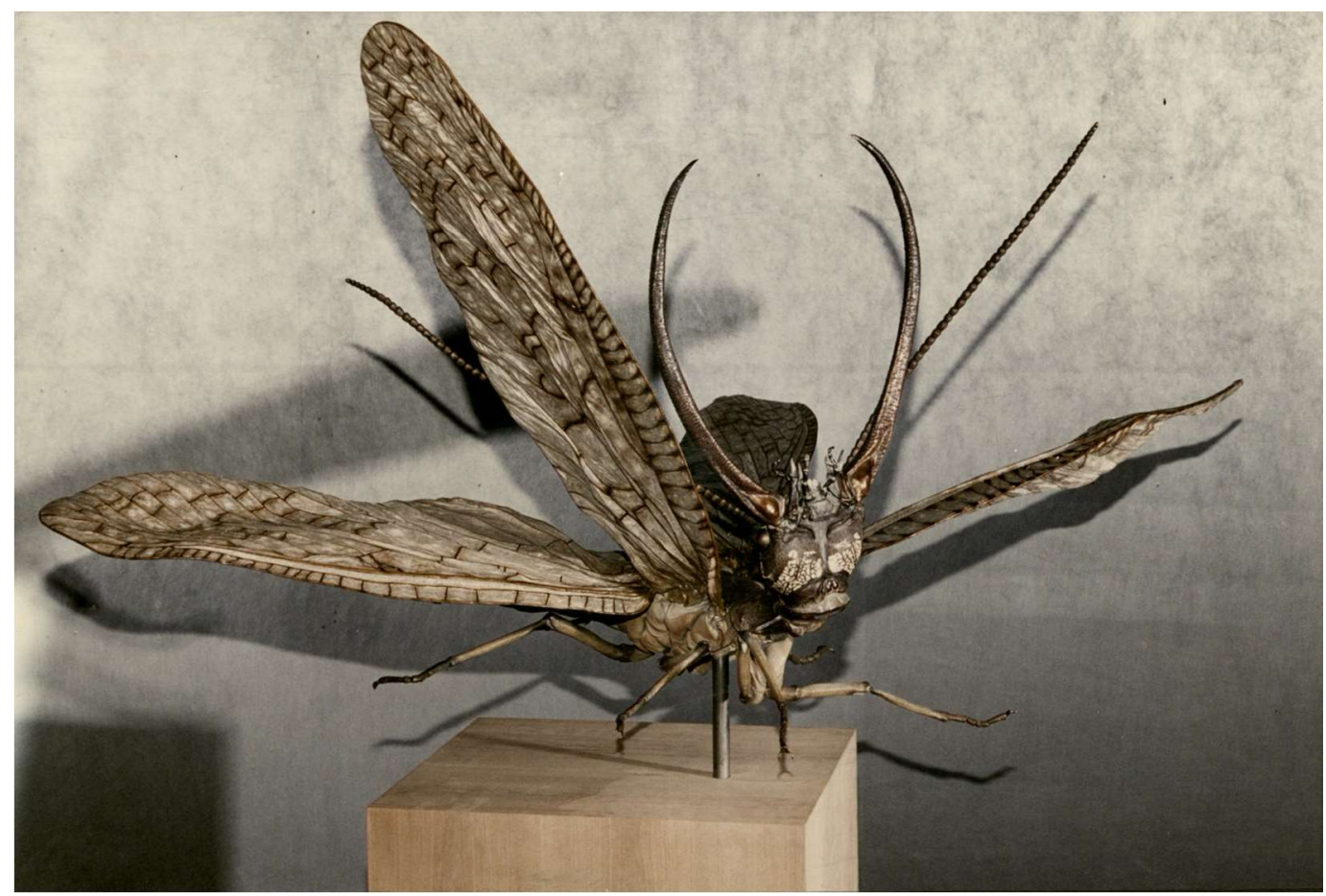

Figure 4. Bronze sculpture of adult dobsonfly, C. cornutus (L.), exhibited at the Fairbanks Museum and Planetarium in Vermont, United States (artist Adam Pasamanick, dimensions $1.82 \mathrm{~m}$ high $\times 1.52 \mathrm{~m}$ wide $\times 1.21 \mathrm{~m}$ long).

\section{Anatomical, Physiological, and Behavioral Adaptations for Life in Water}

Within Neuropterida, Megaloptera are remarkable because of their long-lived larval stage, which is exclusively adapted to an aquatic life style. Only two of 15 families of Neuroptera, Nevrorthidae, and Sisyridae, have aquatic larvae, and all Raphidioptera have an entirely terrestrial life cycle [20]. The anatomy, physiology, and behavior of the megalopteran larva are specialized for an aquatic predatory habit. Each of the higher taxa (Sialidae, Chauliodinae, Corydalinae) occupy at most slightly differentiated spatial and functional niches. Larval sialids are small (10-20 mm body length), typically live for 1-2 years, and are found in both lotic and lentic habitats. Larval corydalids may be large (20-80 mm body length), and long-lived (2-5 years). Corydalids are commonly found in mountain streams, but have been found in a wide variety of aquatic habitats including large rivers, swamps, and water-filled vegetation [35].

Megaloptera larvae have variously patterned or somewhat uniformly colored heads and thoracic nota (mostly pronota). A pattern, because of muscle attachment marks, might serve as camouflage; however, larval coloration can be generally considered cryptic. In the New World, Corydalus dobsonfly larvae tend to be dusky-brown to blackish and live in dark, rocky substrates. Larvae of Chloronia species have a uniformly reddish color, sometimes with four dark dots on the pronotum, and they live in gravel, rock, or deposited organic matter of similar or darker tones. Larvae of Platyneuromus species are yellowish-patterned and live in pale to grayish sandy or rocky limestone and travertine substrates. Often the hellgrammite cuticle becomes impregnated with materials carried by their native streams (A.A.-C., A.C.-R., personal observations). The cephalic capsule is flattened, robust, and 
heavily sclerotized, and prognathous to subprognathous with well-developed chewing mouthparts. The mandibles are robust and sharply pointed, nearly as long as the larval head and equipped with two to four preapical sharp teeth, which are adapted for their predatory habits. The antennae are short, with four articles in Sialidae and Chauliodinae and five in Corydalinae; a peg organ with minute spine-like sensilla is present on the apical part of the second antennomere of Chauliodinae and a spine-like or conical sensilla is on the same region in Corydalinae and Sialidae. The musculature of the head has been described for Corydalus cornutus (L., 1758) [57] and for Neohermes sp. [58].

Larvae of Megaloptera are visually capable, as they have been observed to react to the sight presence of prey. Spectral sensitivity has not been investigated in the group, but responses to UV, blue, and green have been observed in larvae of Corydalus (A.A.-C., personal observation). The first-instar larva of Sialis is planktonic and positively phototactic; conversely, later instars are bottom-dwellers and negatively phototactic. The light sensitive organs are situated anterolaterally, just before the antennal insertions; they are composed of six fully developed stemmata, arranged either with five peripheral ones arranged as a pentagon around a central stemma (Corydalinae and Chauliodinae) or as curved, anterior and posterior rows (Sialidae and Chauliodinae). The retina of each stemma is concave and two-tiered with around 40 retinular cells (Sialidae) or composed of hundreds of retinular cells (Corydalinae) whose rhabdomeres are arranged as an irregular net $[59,60]$. Although these stemmata are probably not image-resolving organs, laboratory studies provide evidence for highly sensitive eyes (A.A.-C., personal observation).

The thorax is flattened and robust, with the prothorax longer than meso- and metathoraces and a heavily sclerotized and quadrangular pronotum; the basisternum is heavily sclerotized; the forelegs are slightly shorter than the mid- and hindlegs and are used for digging behavior for species that burrow into dry streambeds; each tarsus consists of a cylindrical basitarsus, which bears a pair of simple claws distally [5,57]. These traits may relate to a life in rocky streams with riffles and strong currents, the habitat of corydaline larvae.

The abdomen is elongate, 10-segmented, soft and muscular, flattened, and becoming narrower posteriorly. Paired lateral filaments (tracheal gills) are present on segments 1-7 (Sialidae) or 1-8 (Corydalidae), generally covered with rows of long sensilla, which may be related to sensing both prey and predators. Lateral filaments also have thin cuticle and a tracheal trunk with numerous branches, thus being involved in respiration, particularly in Sialidae and Chauliodinae [5]. Larvae also have two pairs of thoracic spiracles and eight pairs of abdominal spiracles for oxygen uptake directly from atmospheric air. Segment 10 of Sialidae has a long and tapered median filament, which is covered with long hair-like sensilla, whereas in Corydalidae there is a pair of prolegs, each of which bears a lateral filament and two hook-like claws to firmly attach to the substrate. Megaloptera larvae can swim; members of both families can make undulating movements with the abdomen, probably as a defensive response against predation and cannibalism, but also useful for dispersion [61]. Abdominal segment 8 of Chauliodinae has the spiracles located dorsally, sometimes at the ends of long respiratory tubes, which may be used as 'snorkels' to breathe at the water surface [62]. Some species of this subfamily are adapted to live in stagnant water, whereas others are found in shallow waters of lotic environments where they can either expose the respiratory tubes to atmospheric oxygen or stay under water, depending on oxygen concentrations [5]. Generally, larvae of Corydalinae are adapted to well-oxygenated streams; they have tripartite ventral tufts of tracheal gills close to the ventral base of each lateral filament on the first seven abdominal segments; these gills are involved in gas exchange, and it is believed they do not participate in osmoregulation, but this role is taken by the hindgut [5]. The abdominal cuticle has a layer of highly modified setae of several types, which may be classified as macro- or microsetae. Corydalinae larvae have both types, with macrosetae erect and varying in morphology, often subglobose and canaliculate with open tips; microsetae are generally star- or scale-shaped and decumbent. These modified setae are probably involved in chemoreception or sensing the current flow, but physiological research on these structures is lacking. Most fishfly and 
alderfly larvae lack thick tergal macrosetae, but some Chauliodinae genera have thin, subglobose, and apparently closed macrosetae [35,63].

\section{Responses to Threats of Water Pollution and Climate Change}

Some of the strongest threats to megalopteran larvae are pollution, eutrophication, and other forms of freshwater and riparian habitat degradation, as a consequence of unregulated human population growth, including expansion of urban areas, deforestation, and water pollution from different sources, such as agricultural production (fertilizers and pesticides from crop production, sewage from animal operations), sewage from pets, petrochemical runoff from motorways, sediment from construction activities, sediment from bank erosion in storm surges caused by rapid runoff from impervious surfaces, and more [64]. Several species with widespread distribution appear to tolerate moderate habitat disturbance, such as Corydalus cornutus in North America, C. luteus in Middle America, and C. armatus in South America [46,65] (A.A.-C., A.C.-R., personal observations), yet formal documentation of the degree of resistance is still incomplete. Other species are more restricted in distribution and limit their presence to pristine conditions, and probably are intolerant and vulnerable to habitat alteration. Invasive species like rainbow trout (Oncorhynchus mykiss (Walbaum, 1972)) and red swamp crayfish (Procambarus clarkii (Girard, 1852)) may be significant threats to Megaloptera populations, either by competing with or preying on hellgrammites. These species have become the subject of recent research in the Tropical Andes due to their negative effect on fresh water systems, as they are highly aggressive and voracious predators, and spread pathogens to the native fauna $[66,67]$. Megaloptera may also be useful for environmental monitoring and distribution modeling to track and predict their future distributions under various climate change scenarios. Being conspicuous insects, both during their aquatic larval and terrestrial egg/pupal/adult stages, they might also be appropriate subjects for insect conservation studies, and thus could potentially be incorporated into management initiatives for habitat and biodiversity protection.

\section{Conclusions}

Despite its low global diversity of close to 400 described species, Megaloptera is an important and conspicuous component of many benthic macroinvertebrate communities, either in tropical or temperate latitudes, as well as in lentic and lotic systems. Often thought of as representatives of an ancient holometabolous lineage, with generalized predatory habits, detailed studies of behavior and sensory capacities of megalopteran larvae are quite scarce. Estimations of their productivity and population density, particularly in tropical environments, are also neglected areas of research. Modern approaches to larval behavior may prove that these insects have more sophisticated capabilities to locate and capture prey than previously realized. Recently, a fairly complete scheme of alpha taxonomy and phylogeny has emerged for this group, although specific phylogenetic issues have yet to be tested or corroborated with cutting-edge molecular techniques; many species level larval descriptions are still missing. Tolerance values of larvae of many species are unknown, and there is no comparative global database from reliable empirical sources. The cultural value and relevance of the group as a source of human food offer opportunities for original research in ethnozoology and novel findings of potential resources.

Author Contributions: Conceptualization: S.L.R.-G., A.A.-C., and A.C.-R.; Investigation: S.L.R.-G. and A.A.-C.; Writing-Original Draft: S.L.R.-G. and A.A.-C.; Writing-Review and Editing: S.L.R.-G., A.A.-C., and A.C.-R.; Visualization: A.A.-C. and A.C.-R.

Funding: This research is based on work supported in part by Project UNAM-DGAPA-PAPIIT IN207517 "Aportaciones a la taxonomía y filogenia del orden Neuroptera (Insecta) en México" (A.C.-R.).

Acknowledgments: We thank Socorro Tapia-Tinajero from library services for help with obtaining references, and Susana Guzmán-Gómez from the microscopy laboratory for help with imaging, both from Instituto de Biología-UNAM; thanks to Mauricio Rodriguez Herrera (professor of English as a Second Language) for English style revision; S.L.R.-G. thanks support from Instituto de Biología-UNAM through a postdoctoral stay from February through September 2018; A.A.-C. thanks Angela Aristizabal, Daniela García, Diego Gómez, Julián Arias, 
and Juan Carlos Quijano, from Universidad de los Andes, Colombia, for help during field work and general support; we also thank issue editors John Morse and Peter Adler, as well as associate editor Barbara Wang and two anonymous reviewers, for many useful corrections and suggestions.

Conflicts of Interest: The authors declare no conflict of interest.

\section{References}

1. Ponomarenko, A.G. Superorder Myrmeleontidea Latreille, 1802 (=Neuropteroidea Handlirsch, 1903). In History of Insects, 1st ed.; Rasnitsyn, A.P., Quicke, D.L., Eds.; Kluwer Academic Publishers: Dordrecht, The Netherlands, 2002; pp. 176-192, ISBN 14-020-0026-X.

2. Grimaldi, D.; Engel, M.S. Evolution of the Insects; Cambridge University Press: Cambridge, NY, USA, 2005; p. 755. ISBN 0-521-82149-5.

3. Contreras-Ramos, A. Systematics of the Dobsonfly Genus Corydalus (Megaloptera: Corydalidae). Thomas Say Publications in Entomology: Monographs; Entomological Society of America: Annapolis, MD, USA, 1998; p. 360. ISBN 0-938522-70-1.

4. Cao, C.; Liu, X. Description of the final-instar larva and pupa of Acanthacorydalis orientalis (McLachlan, 1899) (Megaloptera: Corydalidae) with some life history notes. Zootaxa 2013, 3691, 145-152. [CrossRef]

5. New, T.R.; Theischinger, G. Megaloptera (Alderflies, Dobsonflies) Handbuch der Zoologie; Walter de Gruyter: Berlin, Germany, 1993; Volume 4, p. 102.

6. Glorioso, M.J.; Flint, O.S., Jr. A review of the genus Platyneuromus (Insecta: Neuroptera: Corydalidae). Proc. Biol. Soc. Wash. 1984, 97, 601-614.

7. Ramírez-Ponce, A.; Garfias-Lozano, G.; Contreras-Ramos, A. The nature of allometry in an exaggerated trait: The postocular flange in Platyneuromus Weele (Insecta: Megaloptera). PLoS ONE 2017, 12, e0172388. [CrossRef]

8. Zhao, C.; Liu, X.; Yang, D. Wing base structural data support the sister relationship of Megaloptera and Neuroptera (Insecta: Neuropterida). PLoS ONE 2014, 9, e114695. [CrossRef] [PubMed]

9. Liu, X.Y.; Wang, Y.J.; Shih, C.K.; Ren, D.; Yang, D. Early evolution and historical biogeography of fishflies (Megaloptera: Chauliodinae): Implications from a phylogeny combining fossil and extant taxa. PLoS ONE 2012, 7, e40345. [CrossRef] [PubMed]

10. Winterton, S.L.; Hardy, N.B.; Wiegmann, B.M. On wings of lace: Phylogeny and Bayesian divergence time estimates of Neuropterida (Insecta) based on morphological and molecular data. Syst. Entomol. 2010, 35, 349-378. [CrossRef]

11. Wang, Y.; Liu, X.Y.; Winterton, S.L.; Yang, D. The first mitochondrial genome for the fishfly subfamily Chauliodinae and implications for the higher phylogeny of Megaloptera. PLoS ONE 2012, 7, e47302. [CrossRef]

12. Liu, X.Y.; Lü, Y.; Aspök, H.; Yang, D.; Aspök, U. Homology of the genital sclerites of Megaloptera (Insecta: Neuropterida) and their phylogenetic relevance. Syst. Entomol. 2015, 41, 256-286. [CrossRef]

13. Engel, M.S.; Winterton, S.L.; Breitkreuz, L.C.V. Phylogeny and evolution of Neuropterida: Where have wings of lace taken us? Annu. Rev. Entomol. 2018, 63, 531-551. [CrossRef]

14. Cover, M.R.; Resh, V.H. Global diversity of dobsonflies, fishflies, and alderflies (Megaloptera; Insecta) and spongillaflies, nevrorthids, and osmylids (Neuroptera; Insecta) in freshwater. Hydrobiologia 2008, 595, 409-417. [CrossRef]

15. Monserrat, V.J. Los megalópteros de la Península Ibérica (Insecta, Neuropterida, Megaloptera, Sialidae). Graellsia 2014, 70, 9. [CrossRef]

16. Bowles, D.; Contreras-Ramos, A. First record of the family Sialidae (Megaloptera) from Thailand and description of the female and putative larva of Indosialis bannaensis. Zootaxa 2016, 4114, 485-491. [CrossRef]

17. Jung, S.W.; Vshivkova, T.S.; Bae, Y.J. DNA-based identification of South Korean Megaloptera larvae with taxonomic notes. Can. Entomol. 2016, 148, 123-139. [CrossRef]

18. Archangelsky, M.; Pessacq, P.; Berrondo, M. Description of the larva of Ilyobius chilensis (McLachlan) (Megaloptera: Sialidae) and notes on the adult morphology. Zootaxa 2017, 4318, 177-186. [CrossRef]

19. Misof, B.; Liu, S.; Meusemann, K.; Peters, R.S.; Donath, A.; Mayer, C.; Frandsen, P.B.; Ware, J.; Flouri, T.; Beutel, R.G.; et al. Phylogenomics resolves the timing and pattern of insect evolution. Science 2014, 346, 763-767. [CrossRef] 
20. Winterton, S.L.; Lemmon, A.R.; Gillung, J.P.; Garzon, I.J.; Badano, D.; Bakkes, D.K.; Beitkreuz, L.C.V.; Engel, M.S.; Lemmon, E.M.; Liu, X.Y.; et al. Evolution of lacewings and allied orders using anchored phylogenomics (Neuroptera, Megaloptera, Raphidioptera). Syst. Entomol. 2017, 43, 330-354. [CrossRef]

21. Shcherbakov, D.E. Permian ancestors of Hymenoptera and Raphidioptera. ZooKeys 2013, 358, 45-67. [CrossRef] [PubMed]

22. Wang, Y.; Liu, X.; Garzón-Orduña, I.J.; Winterton, S.L.; Yan, Y.; Aspöck, U.; Aspöck, H.; Yang, D. Mitochondrial phylogenomics illuminates the evolutionary history of Neuropterida. Cladistics 2016, 33, 617-636. [CrossRef]

23. Jepson, J.E.; Heads, S.W. Fossil Megaloptera (Insecta: Neuropterida) from the Lower Cretaceous Crato Formation of Brazil. Zootaxa 2016, 4098, 134-144. [CrossRef]

24. Wichard, W.; Chatterton, C.; Ross, A. Corydasialidae fam. n. (Megaloptera) from Baltic Amber. Insect Syst. Evol. 2005, 36, 279-284. [CrossRef]

25. Archibald, S.B.; Makarkin, V.N. The second genus and species of the extinct neuropteroid family Corydasialidae, from early Eocene McAbee, British Columbia, Canada: Do they belong to Megaloptera? Zootaxa 2015, 4040, 569-575. [CrossRef]

26. Beutel, R.G.; Friedrich, F.; Yang, X.; Ge, S. Insect Morphology and Phylogeny, 1st ed.; De Gruyter: Berlin, Germany, 2014; p. 516, ISBN 978-3110262636.

27. Kristensen, N.P. Phylogeny of insect orders. Annu. Rev. Entomol. 1981, 26, 135-157. [CrossRef]

28. Beutel, R.G.; Friedrich, F.; Aspöck, U. The larval head of Nevrorthidae and the phylogeny of Neuroptera (Insecta). Zool. J. Linn. Soc. Lond. 2010, 158, 533-562. [CrossRef]

29. Beutel, R.G.; Friedrich, F.; Hörnschemeyer, T.; Pohl, H.; Hünefeld, F.; Beckmann, F.; Meier, R.; Misof, B.; Whiting, M.F.; Vilhelmsen, L. Morphological and molecular evidence converge upon a robust phylogeny of the megadiverse Holometabola. Cladistics 2011, 27, 341-355. [CrossRef]

30. Van der Weele, H.W. Megaloptera (Latreille), monographic revision. In Collections Zoologiques du Baron Edm. de Selys Longchamps Fasc. V (Premiere partie), 1st ed.; HathiTrust's Digital Library: Bruxelles, Belgium, 1910; p. 93.

31. Contreras-Ramos, A. Is the family Corydalidae (Neuropterida, Megaloptera) a monophylum? Denisia 2004, 13, 135-140.

32. Contreras-Ramos, A. Phylogenetic review of dobsonflies of the subfamily Corydalinae and the genus Corydalus Latreille (Megaloptera: Corydalidae). Zootaxa 2011, 2862, 1-38. [CrossRef]

33. Glorioso, M.J. Systematics of the dobsonfly subfamily Corydalinae (Megaloptera: Corydalidae). Syst. Entomol. 1981, 6, 253-290. [CrossRef]

34. Cardoso-Costa, G.; Azevêdo, C.A.S.; Ferreira, N., Jr. New genus and new species of Chauliodinae (Insecta: Megaloptera: Corydalidae) from Brazil. Zootaxa 2013, 3613, 391-399. [CrossRef]

35. Cover, M.R.; Bogan, M.T. Minor Insect Orders. In Thorp and Covich's Freshwater Invertebrates: Ecology and General Biology, 4th ed.; Thorp, J.H., Rogers, D.C., Eds.; Elsevier: London, UK, 2015; Volume 1, pp. 1059-1072.

36. Liu, X.Y.; Hayashi, F.; Yang, D. Phylogeny of the family Sialidae (Insecta: Megaloptera) inferred from morphological data, with implications for generic classification and historical biogeography. Cladistics 2015, 31, 18-49. [CrossRef]

37. Flint, O.S., Jr.; Evans, E.D.; Neunzig, H.H. Megaloptera and aquatic Neuroptera. In An Introduction to the Aquatic Insects of North America, 4th ed.; Merritt, R.W., Cummins, K.W., Berg, M.E., Eds.; Kendall Hunt: Dubuque, IA, USA, 2008; pp. 425-437. ISBN 978-0757563218.

38. Azam, K.M.; Anderson, N.H. Life history and habits of Sialis rotunda and S. californica in Western Oregon. Ann. Entomol. Soc. Am. 1969, 62, 549-558. [CrossRef]

39. Ardila-Camacho, A.; Contreras-Ramos, A. The Megaloptera (Insecta: Neuropterida) of Colombia. Aquat. Insects 2018, 3, 297-353. [CrossRef]

40. Hayashi, F.; Nakane, M. Radio tracking and activity monitoring of the dobsonfly larva, Protohermes grandis (Megaloptera: Corydalidae). Oecologia 1989, 78, 468-472. [CrossRef]

41. Fuller, R.L.; Rand, P.S. Influence of substrate type on vulnerability of prey to predacious aquatic insects. J. $N$. Am. Benthol. Soc. 1990, 9, 1-8. [CrossRef]

42. Hayashi, F. Nanocladius (Plecopteracoluthus) asiaticus sp. n. (Diptera: Chironomidae) phoretic on dobsonfly and fishfly larvae (Megaloptera: Corydalidae). Aquat. Insects 1998, 20, 215-229. [CrossRef] 
43. Evans, E.D. A Study of the Megaloptera of the Pacific Coastal Region of the United States. Ph.D. Thesis, Oregon State University, Corvalis, OR, USA, 1972; p. 210.

44. Fashing, N.J. A novel habitat for larvae of the fishfly Chauliodes pectinicornis (Megaloptera: Corydalidae). Banisteria 1994, 3, 25-26.

45. Smith, E.L. Biology and structure of the dobsonfly, Neohermes californicus (Walker) (Megaloptera: Corydalidae). Pan Pac. Entomol. 1970, 46, 142-150.

46. Contreras-Ramos, A. Mating behavior of Platyneuromus (Megaloptera: Corydalidae), with life history notes on dobsonflies from Mexico and Costa Rica. Entomol. News 1999, 110, 125-135.

47. Geijskes, D.C. Notes on Megaloptera from the Guyanas, S. Am. In Progress in World's Neuropterology; Gepp, J., Aspöck, H., Hölzel, H., Eds.; Food and Agriculture Organization: Graz, Austria, 1984; pp. 79-84.

48. Contreras-Ramos, A. Richard W. Merritt, Kenneth W. Cummins y Martin B. Berg (eds.). 2008. An introduction to the aquatic insects of North America, 4a edición. Kendall/Hunt Publishing Company, Dubuque, 1158 p. + CD con clave interactive [book review]. Rev. Mex. Biodivers. 2010, 81, 593-595.

49. Cover, M.R.; Seo, J.H.; Resh, V.H. Life history, burrowing behavior, and distribution of Neohermes filicornis (Megaloptera: Corydalidae), a long-lived aquatic insect in intermittent streams. West. N. Am. Nat. 2015, 75, 474-490. [CrossRef]

50. Contreras-Ramos, A. Megaloptera. In Macroinvertebrados Bentónicos Sudamericanos-Sistemática y Biología; Domínguez, E., Fernández, H.R., Eds.; Fundación Miguel Lillo: Tucumán, Argentina, 2009; pp. 233-245, ISBN 978-950-668-015-2.

51. Contreras-Ramos, A. Notes on some Neotropical Alderflies (Sialidae: Megaloptera). Ann. Entomol. Soc. Am. 2008, 101, 808-814. [CrossRef]

52. Roldán-Pérez, G. Guía Para el Estudio de los Macroinvertebrados Acuáticos del Departamento de Antioquia, 1st ed.; FEN Colombia, Colciencias: Bogotá, Colombia, 1998; p. 217, ISBN 958-9129-04-8.

53. Buzzi, Z.J.; Miyazaki, R.D. Entomologia Didática, 3th ed.; Editora da UFPR: Curitiba, Brazil, 1999; p. 306, ISBN 8573350318.

54. Shepard, W.D. Pigs as corydalid predators. Pan Pac. Entomol. 2004, 80, 66.

55. Epperson, C.R.; Short, R.A. Annual Production of Corydalus cornutus (Megaloptera) in the Guadalupe River, Texas. Am. Midl. Nat. 1987, 118, 433-438. [CrossRef]

56. Bowles, D.E. Life history and variability of secondary production estimates for Corydalus cornutus (Megaloptera: Corydalidae) in an Ozark Stream. J. Agric. Entomol. 1990, 7, 61-70.

57. Kelsey, L.P. The skeleto-muscular mechanism of the dobsonfly. Corydalus cornutus Part I. Head and prothorax. CUAES Monogr. 1954, 34, 1-42.

58. Beutel, R.G.; Friedrich, F. Comparative study of larval head structures of Megaloptera (Hexapoda). Eur. J. Entomol. 2008, 105, 917-938. [CrossRef]

59. Yamamoto, K.; Toh, Y. The fine structure of the lateral ocellus of the dobsonfly larva. J. Morph. 1975, 146, 415-430. [CrossRef]

60. Paulus, H.F. Comparative morphology of the larval eyes of Neuropteroidea. In Recent Research in Neuropterology (Proceedings of the 2nd International Symposium on Neuropterology, 21-23 August); Gepp, J., Aspöck, H., Hölzel, H., Eds.; Food and Agriculture Organization: Graz, Germany, 1986; pp. 157-164.

61. Cao, C.; Liu, Z.; Chen, S.; Tong, C. The swimming behavior of the aquatic larva of Neoneuromus ignobilis (Megaloptera: Corydalidae: Corydalinae). Acta Ent. Sin. 2012, 55, 133-138.

62. Takeuchi, Y.; Hoshiba, H. The life histories of three species of Corydalidae (Megaloptera) from Japan. Aquat. Insects 2012, 34, 55-63. [CrossRef]

63. Contreras-Ramos, A.; Harris, S.C. The immature stages of Platyneuromus (Corydalidae), with a key to the genera of larval Megaloptera of Mexico. J. N. Am. Benthol. Soc. 1998, 17, 489-517. [CrossRef]

64. Sánchez-Bayo, F.; Wyckhuys, K.A.G. Worldwide decline of the entomofauna: A review of its drivers. Biol. Conserv. 2019, 232, 8-27. [CrossRef]

65. Barbour, M.T.; Gerritsen, J.; Snyder, B.D.; Stribling, J.B. Rapid Bioassessment Protocols for Use in Streams and Wadeable Rivers: Periphyton, Benthic Macroinvertebrates and Fish, 2nd ed.; EPA 841-B-99-002; U.S. Environmental Protection Agency, Office of Water: Washington, DC, USA, 1999; p. 339. 
66. Martín-Torrijos, L.; Sandoval-Sierra, J.V.; Muñoz, J.; Diéguez-Uribeondo, J.; Bosch, J.; Guayasamin, J.M. Rainbow trout (Oncorhynchus mykiss) threaten Andean amphibians. Neotrop. Biodiver. 2016, 2, $26-36$. [CrossRef]

67. Arias-Pineda, J.; Pedroza-Martínez, D.R. Presencia del cangrejo rojo Procambarus clarkii (Girard, 1852) en la sabana de Bogotá, Colombia. Bol. Soc. Entomol. Aragon. 2018, 62, 283-286. 